Kyoto University,

Graduate School of Economics

Discussion Paper Series

\title{
BEYOND THUNDERDOME?
}

\section{THE PROSPECTS OF FEDERAL GREENHOUSE GAS CAP-AND-TRADE IN AUSTRALIA}

\section{ELENAAYDOS AND SVEN RUDOLPH}

Discussion Paper No. E-17-008

Graduate School of Economics Kyoto University

Yoshida-Hommachi, Sakyo-ku

Kyoto City, 606-8501, Japan

November, 2017 


\section{BEYOND THUNDERDOME?}

\section{THE PROSPECTS OF FEDERAL GREENHOUSE GAS CAP-AND-TRADE IN AUSTRALIA ${ }^{\mathrm{i}}$ \\ Elena Aydos and Sven Rudolph ${ }^{\text {ii }}$}

1 Introduction

"All we want is life beyond the Thunderdome", is a line made famous by Tina Turner in the title song of the 1985 Mad Max movie. In Thunderdome, a gladiatorial arena in a post-apocalyptic world, conflicts are resolved by duels to death. Not as violently, but certainly as fiercely political battles have been fought in Australia over greenhouse gas (GHG) cap-and-trade in the early 2000s. Increasingly however, the informed public and many of the political stakeholders have craved for a "life beyond".

The Paris Agreement and the respective Nationally Determined Contributions (NDC) as well as the merits of cap-and-trade and its spreading across the globe and all governance levels could also help in reviving the idea. However, with Australia having some of the highest per capita GHG emissions, being the world's leading coal exporter, and its political stakeholders still licking wounds from previous political battles, the question arises: Is there really a second chance for sustainable GHG capand-trade in Australia, a "life" beyond Thunderdome"?

In this chapter, we answer this question by evaluating Australia's former GHG cap-and-trade initiatives based on sustainability criteria. Against the background of Public Choice theory we then analyse the reasons for the eventual political failure of earlier GHG cap-and-trade in Australia and predict the chances of reviving any of the former approaches. We mainly argue that earlier cap-andtrade schemes in Australia showed a lot of merits and that, despite of ongoing partisan feuding, there are political chances for GHG cap-and-trade to live "beyond Thunderdome".

2 Climate policy, sustainable cap-and-trade, and the politico-economic background The Paris Agreement is certainly a diplomatic success, but needs to be substantiated by convincing policies. The Agreement obliges the global society to "[h]olding the increase in the global average temperature to well below $2^{\circ} \mathrm{C}$ above pre-industrial levels and pursuing efforts to limit the temperature increase to $1.5^{\circ} \mathrm{C}$ above pre-industrial levels" ${ }^{\text {iii }}$ However, the (I)NDC submitted to the UNFCCC until May 2016, even if fully implemented, fall short of the reductions necessary for following the low-cost 
$2{ }^{\circ} \mathrm{C}$ scenario. ${ }^{\text {iv }}$ And while the Paris Agreement obliges the parties to a "progression over time"v with respect to their climate protection efforts, there is still substantial need for convincing policy approaches.

Domestic GHG cap-and-trade is a promising way of substantiating the Paris Agreement. The agreement explicitly allows the use of "internationally transferred mitigation outcomes", or, in more economic terms, the trading of emission rights or credits. Emissions trading or cap-and-trade has almost unanimously been supported by economists on the grounds of environmental effectiveness and economic efficiency. ${ }^{\mathrm{vi}}$ Recently, it has been shown that a sustainable design, not only taking into account effectiveness and efficiency but also social justice requirements, is possible. ${ }^{\text {vii }}$ Surprisingly, the resulting design recommendations do not exhibit major contradictions between environmental, economic, and social goals, but rather point to the same direction. Following this approach would hence directly answer to the Paris Agreement's urge to "reflect equity". viii Not least, linking domestic schemes can significantly improve the sustainability of GHG cap-and-trade, ${ }^{\text {ix }}$ and with domestic schemes becoming more widespread, extending not only to several continents and countries but also to all governance levels from local to supra-national, ${ }^{\mathrm{x}}$ this option becomes even more promising.

However, the feasibility of sustainable GHG cap-and-trade suffers from a variety of political barriers. Public Choice, the economic theory of politics, provides a set of arguments on why rational, self-interested political actors such as voters, interest groups, bureaucrats, and politicians would not support ambitious market-based approaches to environmental protection. ${ }^{\text {xi }}$ It substantiates a "market tendency for the political process to resist market mechanisms for rationing scarce environmental resources"xii by showing that only less influential political stakeholders support pricing instruments such as environmental taxes or cap-and-trade, while the most potent ones oppose them. Empirical studies support this view to some extent. ${ }^{\text {xiii }}$ Thus, while the restrictive assumptions of Public Choice certainly limit its explanatory and predictive power, Public Choice can still provide a worst-case scenario for the political feasibility of sustainable GHG cap-and-trade. 


\section{GHG cap-and-trade in Australia}

In 2008, the Labor government under Prime Minister Kevin Rudd proposed the introduction of an emissions trading scheme known as the Carbon Pollution Reduction Scheme (CPRS) ${ }^{\text {xiv }}$ A thorough policy development process was put in place, starting with a Green Paper on ETS design issues in July. This was followed by the release of a comprehensive independent report on the impacts of climate change on the Australian economy, ${ }^{\mathrm{xv}}$ the Treasury modelling and a White Paper in December. ${ }^{\mathrm{xvi}} \mathrm{In}$ 2009 and 2010, the Rudd government introduced three packages of legislation to implement the scheme. The CPRS Bill passed the House of Representatives. In a historical political turn, six days before the Senate vote, Tony Abbott won the Opposition leadership replacing Malcolm Turnbull and opposed the bills. ${ }^{\text {xvi }}$ The Greens party voted with Abbott against the CPRS.

After a second failed attempt in 2010, Prime Minister Rudd deferred the CPRS legislation until the end of the first commitment period of the Kyoto Protocol in 2012. The decision to postpone the CPRS Bills, the chief policy mechanism to deal with what Rudd called the 'moral challenge of our generation', cost Prime Minister Rudd his position as a Labor Leader and Prime Minister. ${ }^{\text {xviii }}$

In July 2011, Prime Minister Julia Gillard proposed the introduction of a carbon market called the Carbon Pricing Mechanism (CPM). ${ }^{\text {xix }}$ This time backed by the Greens Party, the legislative package passed in Parliament in November 2011, and received Royal Assent in December 2011. ${ }^{\mathrm{xx}}$ The CPM commenced on 1 July 2012, coinciding with the end of the first commitment period under the Kyoto Protocol. After two years of a functioning AUS CPM, Australia's new Prime Minister Abbott delivered a campaign promise of abolishing the scheme. A legislative package, also known as the 'carbon tax repeal legislation', passed in the House of Representatives and the Senate and received Royal Assent on 17 July 2014, dismantling the AUS CPM. The legislation entered into effect from 1 July 2014.

Following the abolition of the CPM, ${ }^{\mathrm{xxi}}$ the Coalition Government's main climate change policy instrument became the Emission Reduction Fund (ERF), which was built upon the already existing legal framework for the Carbon Farming Initiative (CFI) through amendments to the CFI Act. ${ }^{\text {xii }}$ The ERF is an incentive-based scheme, in which the Federal Government subsidises sequestration or emission avoidance projects through the direct purchase of offset credit units known as Australian Carbon Credit 
Units (ACCUs). ${ }^{x x i i i}$ The process for purchase of ACCUs is completed via reverse auctions and tenders, ${ }^{\text {xxiv }}$ whereby project proponents compete for the undertaking of emissions abatement projects. The purchaser (in this case, the Government), selects the successful bids to enter into a contract with. ${ }^{\mathrm{xxv}}$

Linked to the ERF is the Safeguard Mechanism (SM), which commenced operations on 1 July 2016 with the passing of the National Greenhouse and Energy Reporting Act 2007 (Cth) and respective amendments made under the CFI Amendment Act. ${ }^{\mathrm{xxvi}}$ The SM is a baseline and credit mechanism covering a relatively small number of high emitters in Australia. The key features of the CPRS, CPM and ERF/SM schemes are compared below and assessed against the sustainability criteria for cap-and-trade.

\subsection{Coverage}

The sustainability criteria on coverage call for mandatory participation of all polluters and coverage of all GHG. ${ }^{\text {xxvii }}$ Such requirements are only partially fulfilled by the CPRS and the CPM, with the CPRS complying with the criteria to the greatest extent, while the ERF/SM fails to comply with the social justice criteria in relation to coverage.

The CPRS fulfilled the mandatory participation criterion and GHG coverage criterion, covering all six GHG listed under the Kyoto Protocol, whilst only partially meeting the requirements in respect to participation of all polluters. The CPRS was designed to be mandatory for approximately 1,000 large polluters from the stationary energy, transport, fugitive emissions, industrial processes and waste sectors, covering approximately $75 \%$ of Australia's emissions ${ }^{\mathrm{xxviii}}$. Within these sectors, only companies emitting 25,000 tonnes or more of $\mathrm{CO}_{2}$-e per year were covered. ${ }^{\text {xix }}$ Excluded from the CPRS were emissions from agriculture, forestry, fugitive emissions from decommissioned underground coal mines, certain synthetic greenhouse gases and emissions from the combustion of biomass.

The CPM was also mandatory to liable companies. It covered approximately 360 large polluters emitting 25,000 tonnes of $\mathrm{CO}_{2}$-e per year or more, responsible for around $60 \%$ of Australia's emissions. ${ }^{\mathrm{xxx}}$ The CPM also covered only four of the six Kyoto GHG, from aluminium smelting, stationary energy, non-legacy waste, transport, ${ }^{\mathrm{xxi}}$ industrial processes and fugitive emissions. The scheme excluded emissions from agriculture, forestry, fugitive emissions from decommissioned coal mines and legacy waste. Road transport and forestry sectors were not covered by the CPM. However, 
the legislation on fuel tax and synthetic GHGs imposed an equivalent carbon price on some business transport emissions, the non-transport use of liquid and gaseous fuels (except natural gas) and synthetic GHGs. ${ }^{\text {xxxii }}$

Of the three schemes, the ERF/SM is the one with the most significant sustainability problems. The voluntary participation in the ERF coexists with a mandatory participation for a very limited number of businesses in the SM, approximately 140 large businesses with annual emissions of over 100,000 tonnes of carbon dioxide equivalent (compared to 25,000 tonnes of $\mathrm{CO}_{2}$-e per year or more under the CPRS and CPM). The ERF/SM covers exclusively direct GHG emissions (scope 1 emissions) from power generation (approximately 57\% GHG emissions from the electricity sector), mining (coal and metal ores), oil and gas extraction, gas supply, manufacturing (including metals, cement and lime), transport (air, sea, rail and road), heavy and civil engineering construction, and (new) waste.

\subsection{Cap}

Sustainable cap-and-trade have stringent volume caps, which are absolute and are set to gradually decrease and are linked to stringent absolute volume reduction targets. ${ }^{\mathrm{xx} x i i i}$ The criteria are partially fulfilled by the CPRS and the CPM, with the ERF/SM lagging behind.

Australia has historically committed to weak reduction targets and the trend has been further exacerbated under the recent Coalition Government. At the time of the CPRS proposal, Australia had committed not to a reduction, but to an increase in emissions to average $108 \%$ of 1990 emissions for the years 2008 to 2012. Beyond 2012, reduction targets were set at $60 \%$ below 2000 levels by 2050 and between $5 \%$ and $15 \%$ below 2000 levels by 2020 . In the event that there is comprehensive international agreement, the ambition of the target could be increased to $25 \%$ below 2000 levels by 2020. In terms of cap, while transitional measures would exclude an absolute cap in the first 12 months of the CPRS, from 2012-13 absolute volume caps would be set by Regulations, based on the indicative national targets in the relevant year.

Functioning under the same federal emission reduction targets, the framework for the CPM provided for a longer transitional period (three years) during which emissions would not be capped under the scheme, disproportionately burdening non-covered sectors. ${ }^{\text {xxxiv }}$ However, from 1 July 2015 onwards, absolute pollution caps would be set by Regulations ${ }^{\mathrm{xxx}}$ reflecting Australia's medium- and 
long-term targets for reducing net greenhouse gas emissions and the different possible trajectories towards it. ${ }^{\mathrm{xxvi}}$

With the absolute caps being set by Regulations, there was no mandatory cap reduction under the CPRS and the CPM. However, absolute caps were expected to gradually decrease, amongst other things, through the adoption of default caps in the absence of Regulations.

The Coalition Government has committed to the lowest level of reduction targets for 2020 (only $5 \%$ reduction based on 2000 levels) and adopted a weak medium-term target of 26-28\% below 2005 levels by 2030. Under the ERF/SM there are no absolute caps. Instead, individual baseline emissions number are set for each facility, calculated based on historical emissions data (highest level of reported emissions for a facility over the historical period 2009-10 to 2013-14), with no mandatory graduation reduction of individual baselines. The ERF/SM once again violates the social justice criteria in relation to the cap.

\subsection{Allocation}

The social justice criteria for the validity of emission rights and the initial allocation would be increasingly fulfilled by the CPRS and the CPM. Both schemes would create and issue emissions permits, each corresponding to 1 tonne of CO2e. During the first 12 months of the CPRS (2011-12), permits would have been allocated at a fixed charge of $\$ 10$ per unit. From 2012-13 there would be auctioning of permits (unit of $1 \mathrm{t}$ of $\mathrm{CO} 2 \mathrm{e} / \mathrm{a}$ ) combined with targeted assistance via free allocation of permits to emissions-intensive trade exposed (EITE) industries and the Coal sector. Assistance would be transitional and the scheme would progressively move towards 100 per cent auctioning.

The framework of the CPM provided for the issue of permits for a fixed price from 1 July 2012 until 30 June 2015, starting at $\$ 23$ per tonne of $\mathrm{CO}_{2}$-e in 2012-13. After 1 July 2015, units would be allocated via auction. During the fixed charge years and the flexible charge years, the Government would issue permits free of charge to EITE sectors under the Jobs and Competitiveness Program. Two categories of eligibility for the Jobs and Competitiveness Program, i.e. moderately emissions-intensive and highly emissions-intensive, would determine the different levels of free allocation. ${ }^{\text {xxvii }}$

In contrast, the sustainability criteria for allocation are entirely violated by the ERF/SM. Under the $\mathrm{ERF} / \mathrm{SM}$ there is no absolute cap and no issue and/or trading of permits. The federal government 
enters into 'carbon abatement contracts' to directly purchase offset credits generated through sequestration or emission avoidance projects. ${ }^{\text {xxviii }}$

\subsection{Revenue Use}

The CPRS and the CPM largely complied with the sustainability criteria for revenue use, as both schemes were set to be revenue neutral. Revenue from the CPRS would have been used to purchase international credits, such as avoided deforestation credits and towards household assistance measures and industry assistance measures.

The CPM provided for cost compensation to low income households and industry, investments in renewable energy and funding for emissions reduction projects in the land sector. Over 50 per cent of carbon price revenue was earmarked for cost compensation of approximately 1 million low-income households. The package effectively delivered a tax reform that compensated beyond the cost increase due to the carbon price. ${ }^{\text {xxix }}$ In addition to tax cuts, pensions, allowances and benefits were increased and there were other benefits to households with special needs.

The Jobs and Competitiveness Program, providing free allocation of permits to EITE sectors, would use another 40 per cent of the revenue collected under the CPM. A Coal Sector Jobs Package and an Energy Security Fund would guarantee free allocation of permits and cash payments to the coal sector, including coal mining and coal-fired electricity generators. A Steel Transformation Plan provided assistance to the Steel sector. Finally, part of the revenue from the CPM would be invested in renewable energy, low pollution and energy efficiency technologies, as well as fund new land-based mitigation measures.

Contrarily, the ERF/SM is a subsidy-based scheme that uses government revenue to purchase offset credits and therefore it is not capable of generating revenue.

\subsection{Flexibility Mechanisms}

The sustainability criteria in respect to flexibility mechanisms allow for banking but disapprove borrowing of permits. ${ }^{\mathrm{xl}} \mathrm{A}$ limited number of offsets that meet stringent requirements is also in line with the sustainability criteria. 
The CPRS and the CPM somewhat complied with the criteria, allowing for banking of units after the fixed charge period, but also allowing for limited borrowing. Under the CPRS, a domestic offsets program offered opportunity to receive free Australian emissions units for sustainable offset projects. The CPRS would also accept international offset units, including certified emission reduction (CERs), emission reduction units (ERUs), removal units (RMUs), prescribed Kyoto units and prescribed nonKyoto international emissions unit. ${ }^{\text {xli }}$

The CPM was linked to the CFI, a domestic voluntary offsets scheme offering a range of abatement and carbon sequestration opportunities in the land sector. The CPM would also link to international schemes from 2015 onwards, up to a limit of $50 \%$ of the participants' liability for the relevant year. ${ }^{\text {xlii }}$

Under the ERF/SM, facility operators can surrender eligible carbon offsets at any time to remain below their baseline. Credits issued under the Emissions Reduction Fund—also known as Australian Carbon Credit Units or ACCUs_-are eligible offsets.

\subsection{Price Management}

The sustainability criteria suggest that market intervention should be kept to the minimum, but if a price collar applies, the price floor and the price ceiling should not be lower than US\$20 and US\$200, respectively. ${ }^{\text {xliii }}$ The CPRS and the CPM would progressively fulfil this requirement, as price flexibility was meant to increase over time.

In the first 12 months of the CPRS, permits would have been sold for a fixed price, with a practical effect of a carbon tax. From 2012-13, permits would be auctioned. In the first four years of auctioning, access to an unlimited store of additional permits issued at a pre-specified fixed price would have the practical effect of a price cap, starting at AU $\$ 40$. These units would not be tradeable or bankable for future use.

Similarly, under the CPM permits were sold during the fixed charge years at AU $\$ 23$ per permit. A price ceiling was in place for the first three flexible charge years. ${ }^{\text {xliv }}$ The original design of the AUS CPM also included a price floor (AU\$15, rising annually by four per cent) in the first three flexible charge years. ${ }^{\mathrm{xlv}}$ However, this feature was removed when the Australia and the European Union declared that they would link the CPM with the European Union Emissions Trading System (EU ETS). ${ }^{x l v i}$ 
It is not possible to assess the ERF/SM against this criterion, given that permits are not issued by the Government under this scheme.

\subsection{Compliance}

According to the sustainability criteria, compliance periods should be short in order to allow for shortterm control over reduction achievements and provide opportunities for immediate penalties and expost emission compensation in the case of non-compliance. Trading periods can be long, only if supplemented by short-term submission requirement for major parts of used emissions rights. Reliable monitoring and quenching penalties are a necessary component of a sustainable cap-and-trade. ${ }^{\text {xlvii }}$ The CPRS and the CPM greatly complied with this criterion, while, once again, the ERF/SM fails to comply.

The compliance cycles of the CPRS and the CPM were the financial year. Both schemes imposed stringent penalties in case of unit shortfall, although it did not include (over)compensation for excess emissions. Penalties were strict under the CPM, with a unit shortfall charge applicable in the first three years (fixed charge period) equivalent to 130 per cent of the ACU fixed price, once again not including

(over)compensation for excess emissions. ${ }^{\text {xlviii }}$ In flexible charge years, the unit shortfall charge was set by regulations and would range between 130 per cent and 200 per cent (default rate) of the benchmark average auction charge for the relevant period. ${ }^{\text {xlix }}$ In case a unit shortfall charge remained unpaid after the due date, an extra penalty calculated at the rate of $20 \%$ per annum (or a lower rate specified in the regulations) on the amount unpaid was due. ${ }^{1}$

In addition to the generous baselines and very limited liability under the SM, the ERF/SM has very weak compliance mechanisms. Participants may opt between one financial year or multi-year periods (two or three-year multi-year periods). The penalty for exceeding the baseline is virtually insignificant, with the option for the participant to adjust the facility's baseline or select a multi-year compliance approach for managing excess emissions.

The Regulator has discretion in applying a range of enforcement options, including the issuing of infringement notices, acceptance of enforceable undertakings, seeking injunctions and pursuing court action. Enforcement options are unlikely to ever be applied given the generous baselines. The Clean Energy Regulator may seek civil penalties through the courts with the maximum amount set at 100 
penalty points per day (currently $\$ 18,000$ per day), to a maximum of 10,000 penalty points in total. In addition to paying the penalty, the facility operator remains under an obligation to rectify an excess emissions situation. This option is also very unlikely to take place, as the civil penalty is considered a last resort and will never apply to businesses that meet legislated safeguard requirements.

\subsection{Supporting Measures}

None of the Australian schemes to date provided for border adjustment to prevent carbon leakage. The main strategy to protect EITE sectors in the CPRS and the CPM was free allocation of permits, which does not comply with the sustainability criteria.

In August 2012, the linking of the EU ETS and Australia's CPM was announced. GHG emissions permits from the EU ETS (European Union Allowances) were to be eligible to be used for compliance under the AUS CPM from July 2015 until July 2018 ('one-way link'). From 1 July 2018, a two-way link would be put in place, with mutual recognition of carbon units between the two ETSs. ${ }^{\text {li }}$

The CPM also allowed for the use of units from credible international carbon markets. However, the most important feature was the negotiated linking with the European Union Emissions Trading System (EU ETS), initially unilateral, which was supposed to commence in 2015.

The ERF/SM currently does not allow for the linking with international units.

\subsection{Impacts from cap-and-trade in Australia}

Ex ante an studies of the CPM show that it was estimated to cause a 10 per cent increase in electricity prices, driving significant changes to the energy sector which would make renewable energy more competitive relative to coal. ${ }^{\text {lii }}$ The Treasury modelling ${ }^{\text {liii }}$ concluded that the impacts on manufacturing output would be small, with some sectors in the economy actually benefiting from the carbon price. .iv $^{\text {. }}$ While the Treasury modelling stated that some emissions-intensive sectors would require transitional assistance, it did not focus on specific sectors/subsectors of the economy in order to inform the appropriate levels of assistance.

Despite the absence of ex ante assessment for specific sectors, in 2011, the Grattan Institute analysed the likely impacts of a carbon price of $A \$ 23$ rising to $A \$ 40$ on a number of industry sectors in Australia. ${ }^{\text {lv }}$ It concluded that the industry support in the form of the proposed free allocation of 
permits to the liquefied natural gas (LNG), coal mining and steel industries was unjustified and costly, putting at risk the environmental efficiency of the scheme and unjustifiably increasing the general costs of carbon reduction elsewhere in the economy, including non-participant sectors and

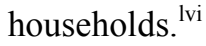

The short period of the scheme's existence did not allow for ex-post studies on the impacts of the AUS CPM to industry, ${ }^{1 v i i}$ except for indications that there has been no harm to the overall economy attributable to the CPM. ${ }^{\text {lviii }}$

In terms of its environmental effectiveness, data published on the Quarterly Update of Australia's National Greenhouse Gas Inventory from June 2012 onwards confirms that the CPM had a real potential to reach meaningful emissions reductions. In fact, emissions went down after implementation of the CPM and, inversely, increased after the repeal of the CPM and implementation of the $\mathrm{ERF} / \mathrm{SM} .^{\mathrm{lix}}$

In sum, a distinct hierarchy of compliance with sustainability criteria can be detected for former and current market-based climate policy approaches in Australia. While the CPRS clearly had the best design, the CPM also did well and even delivered some promising results in the short period of its efficacy. The ERF/SM, however, cannot be considered a sustainable climate policy choice for Australia.

4 The politics of GHG cap-and-trade in Australia

4.1 Voters: The Australian public

The Australian voters' opinion on climate policy has had its ups and downs. ${ }^{1 \mathrm{x}}$ In the early 2000 s, basically, there was strong support for climate action driven e.g. by the 2007 Australian bushfires as well as international events such as the Al Gore movie "An Inconvenient Truth". From 2008 onwards, however, attention switched to the global financial crisis and potential additional costs caused by ambitious climate policy.

Australian voters' position on carbon-cap-and-trade, is mainly determined by the perception of the pricing and revenue recycling design elements. ${ }^{\text {lxi }}$ Early opinion polls show broad support for pricing schemes, which formed the background of former Prime Minister Rudd's pro-active strategy on climate change and the CPRS as well as Prime Minister Gillard's CPM. The later public resistance 
was almost entirely formed by a campaign of the Coalition opposition under the Abbott's leadership, terming the CPM a tax and emphasizing possible increases in households' costs of. Mainly over this issue, in 2013 Australians voted the Gillard government out of office and replaced it by Abbot. It added to the problem, that the revenue recycling was not as easily understood as the pricing itself. The continuing political quarrelling over climate and energy policy, current Prime Minister Turnbull's broken promise to tackle the issue seriously, and the still sticking Abbott tax-tag has left a continuing distrust in Australia's governments' will and skill to deal with climate change.

4.2 Interest groups: Australian environmental organizations, industry groups, and labour unions Major interest groups involved in the debate about GHG cap-and-trade in Australia have been environmental organizations, industry groups, and labour unions.

Environmental non-governmental organizations (NGO) have quite generally been supportive of GHG pricing for over a decade now. ${ }^{\text {xii }}$ They mainly value the absolute limit to GHG emissions. Targets in line with the climate protection necessities, comprehensive coverage, and limits to offsets and free allocation have been major design requirements. Still, NGOs opposed Rudd's CPRS because of hope for an even more stringent scheme. Gillard's CPM, in turn, gained more support, mainly due to the eventual complete CPRS failure. This support for ambitious GHG cap-and-trade continues to date. However, NGOs have changed their strategy from fierce political lobbying to a more cooperative strategy, institutionalized e.g. by the Australian Climate Roundtable. Hopes are that this cooperation with major business associations and labour unions opens more doors for a new GHG cap-and-trade scheme in Australia than continued engagement in the political battles between government and opposition parties. The now increased consensus amongst NGOs on GHG cap-and-trade might also add to NGOs political power. Still, NGOs political influence on a Coalition government is much smaller than on a Labor government, mainly due to limited personal relationships. Not least, compared to industry, Australian NGOs still lack financial and personnel resources. However, industry has lost some of its influence due to a growing gap between individual sectors' positions.

Major parts of the Australian industry have quite substantially changed their position on GHG capand-trade. ${ }^{\text {xiii }}$ However, the extracting industry to this day continues to doubt climate science and opposes GHG cap-and-trade, mainly because of the threat to coal use and exports. The manufacturing 
sector, on the other hand, had shown some level of openness before 2010, then joined the extracting industry in its determined opposition, but recently have become more open again. While international competitiveness remains its major concern, above all else, manufacturing craves for energy and climate policy certainty for long-term investment decisions. Coverage of the industry, transport, and household sectors, international linkages, and a phase-in similar to the CPRS would be design elements most appreciated. Genuine support for GHG cap-and-trade continuous to be provided by the service sector, banks, insurances, and renewable energy companies. Australian labour unions, even including mining sector unions, have also been long-time supporters of GHG cap-and-trade.

\subsection{Bureaucracy: The Department of Environment and Energy}

Civil servants in Australia's ministries below the minister level, more than in other countries, tend to value independence from political parties' ideologies and interest groups' opinions. Still, officials in the Department of the Environment and Energy have an above average motivation to protect the environment in general and the global climate in particular. ${ }^{\text {1xiv }}$ GHG cap-and-trade, though initially seen with some scepticisms, has gained a lot of support within the Department at the working level and is now, even after the failure of the CPRS and CPM and their political legacy, considered to be the most promising approach to domestic and international climate policy.

The Departments political influence mainly stems from its officials' technical expertise in the respective matters and their capability of designing and refining policies. This expertise has been acquired over a period of more than 15 years of working on GHG cap-and-trade, and, as a consequence, despite of the usual personnel shuffling, the Department still disposes of ample policy design know-how, elaborated policy proposals, and supporting data. However, especially in these times of the particular political legacy of GHG cap-and-trade, lower-level civil servants have limited influence on really driving what ends up to be a very political decision made by the governing parties and their cabinet. 


\subsection{Politicians: The Coalition, the Labor Party and the Greens}

Despite of the differences in the positions described above, the major political battle has been fought between political parties. ${ }^{1 \mathrm{xv}}$

Supported mainly by the extracting industry, the conservative-liberal Australian Coalition parties have positioned themselves as opponents of ambitious GHG cap-and-trade. This results partly from an industry-friendly party ideology, but mainly from tactical planning in the campaign leading to the 2013 elections. In order to overcome the Gillard government, Abbott went on a crusaded against the CPM with the tax-tag as its winning weapon. Pounding the tax drum all along, eventually he gained the support of the majority of the Australian electorate and was elected Prime Minister. And immediately he got rid of the CPM, replacing it by the ERF/SM. To this date, even under the Turnbull government, there has been no intention to open a new discussion on a real GHG cap-and-trade scheme.

The Labor Party continues to support GHG cap-and-trade. However, the Rudd government at the time missed its chance to implement the CPRS mainly due to unnecessary political manoeuvring at times when public support for climate action was the strongest and industry resistance the least. And while Gillard revived the idea, she also fed Abbott's campaign by publicly admitting that the CPM with its initially fixed price could be termed a tax. Labor's current policy proposal builds on a sectoral approach and a two-step phase-in of cap-and-trade, which starts with an intensity baseline-and-credits scheme and then moves on to a comprehensive full-fledged cap-and-trade program.

The Green Party, though actually in favour of ambitious GHG cap-and-trade, had its devastating moment when, backed by more fundamental NGOs at the time, they voted against Rudd's CPRS on the basis of a design critique in detail. Having learned the political lesson, they later supported Gillard's CPM. Currently, the Greens still favour an ambitious GHG cap-and-trade program as the best climate policy option to deliver the emissions reductions necessary to meet Australia's INDC target.

In sum, while the fierce battle over GHG cap-and-trade between Australia's political parties continues, the opposing forces are now limited to the Coalition parties and extracting industries. Support, on the other hand, comes from the Labor and Green Parties, the manufacturing and other businesses, labour unions, and NGOs. While a newly elected Labor-led government could certainly 
bring about major change after the 2019 elections, the Coalition's margin for manoeuvring towards a new GHG cap-and-trade scheme seems limited.

\section{Conclusions}

A number of uncoordinated policies have been debated, introduced and dismantled over the past ten years in Australia. Inconsistent approaches towards climate action were fuelled by a toxic political debate, not only around the ideal policy mechanism but around the science of climate change itself.

The CPRS and the CPM were to a great extent compliant with the sustainability criteria for a GHG cap-and-trade and would be improved over time, however the schemes lacked political support. The ERF/SM, while politically feasible, has not been capable to generate meaningful emissions reductions and encourage the transition to a low emissions economy in Australia.

Of the three schemes that were compared, the ERF/SM is by far the worse in terms of compliance with sustainability criteria. Some of the most concerning features are the incapacity to raise revenue (exclusively relying on substantial government funding) ${ }^{1 \mathrm{xvi}}$ and the lack of stringency of the baselines under the SM.

Despite the complex political landscape, Australia will be increasingly pressured to fulfil its commitments under the Paris Agreement and it is clear that the measures currently in place are insufficient. The lack of political certainty has harmed investment and now some new pro-active dynamics are starting to be shaped in the business community. There is scope, therefore, for a cautiously but optimistic view that, under certainly necessary new political leadership, 'the recent tarnishing of cap-and-trade ... will ... turn out to be a temporary departure from a long-term trend of increasing reliance on market-based environmental policy instruments". 1xvii 


\section{Notes}

${ }^{\mathrm{i}}$ Discussion Paper presented at the $18^{\text {th }}$ Global Conference on Environmental Taxation (GCET18), University of Arizona James E. Rogers College of Law, Tucson, September 27-29, 2017. The research was generously supported by the University of Newcastle 2017 International Research Visiting Fellowship (IRVF). Special thanks also goes to the interview partners in Australia and Mashifu Noguchi for helping with the data processing.

${ }^{\text {ii }}$ Dr. Elena Aydos, Lecturer, University of Newcastle Law School, Australia; Dr. Sven Rudolph, Associate Professor, Graduate School of Economics, Kyoto University, Japan. Contact: elena.aydos@newcastle.edu.au.

iii Paris Agreement to the United Nations Framework Convention on Climate Change, opened for signature 26 April 2016, UNTS I-54113 (entered into force 04 November 2016).

${ }^{\text {iv }}$ UNFCC (2016): Aggregate effect of the intended nationally determined contributions - an update (Synthesis report by the secretariat) Bonn.

${ }^{\mathrm{v}}$ Paris Agreement Art 3.

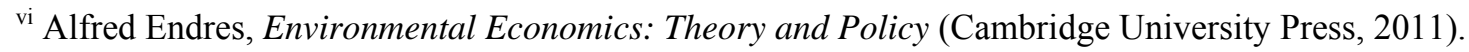

${ }^{\text {vii }}$ Rudolph, S et al. (2012): Towards Sustainable Carbon Markets. In: Kreiser, L et al. (eds.): Carbon Pricing, Growth and the Environment - Critical Issues in Environmental Taxation XI. Cheltenham, UK/Northampton, US: Edward Elgar. 167-183.

viii Paris Agreement Art 3.

${ }^{\text {ix }}$ Rudolph et al. (2017): Developing the North American Carbon Market - Prospects for Sustainable Linking. In: Weishaar, Stefan et al. (eds.) The Green Market Transition: Carbon Taxes, Energy Subsidies and Smart Instrument Mixes - Critical Issues in Environmental Taxation Volume XIX, Cheltenham, UK/Northampton, US: Edward Elgar, 209-230.

${ }^{x}$ ICAP (2017). Emissions Trading Worldwide: Status Report 2017. Berlin: ICAP.

${ }^{\text {xi }}$ Kirchgässner, G/Schneider, F (2003): On the political economy of environmental policy. Public Choice 115(3), 369-396.

${ }^{\text {xii }}$ Hahn, RW (1987): Jobs and environmental quality - some implications for instrument choice. Policy Sciences 20(4), 289-306: 289. 
xiii Schneider, F et al. (2015): Political Economy and Instruments of Environmental Politics

(Cambridge: MIT Press).

${ }^{\text {xiv }}$ Carbon Pollution Reduction Scheme Bill 2009 (Cth) ('CPRS Bill').

${ }^{\mathrm{xv}}$ Ross Garnaut, The Garnaut Climate Change Review: Final Report (Cambridge University Press, 2008) 101.

xvi Department of Climate Change, 'Carbon Pollution Reduction Scheme: Green Paper' (2008); Commonwealth of Australia, 'Australia's Low Pollution Future: The Economics of Climate Change Mitigation' (2008); Department of Climate Change, 'Climate Change Carbon Pollution Reduction Scheme: White Paper' (2008).

${ }^{\text {xvii }}$ See Peter Sopher, Anthony Mansell and Clayton Munnings, 'Australia' (EDF

IETA, 2014) 93, 2.

xviii Ibid.

${ }^{\text {xix }}$ Australian Government, 'Securing a Clean Energy Future: The Australian Government's Climate Change Plan' (2011).

${ }^{\mathrm{xx}}$ Clean Energy Act 2011 (Cth) ('CE Act'); Clean Energy Regulator Act 2011 (Cth); Climate Change Authority Act 2011 (Cth); Australian National Registry of Emissions Units Act 2011 (Cth); Clean Energy (Charges-Customs) Act 2011 (Cth); Clean Energy (Charges-Excise) Act 2011 (Cth); Clean Energy (Consequential Amendments) Act 2011 (Cth); Clean Energy (Household Assistance Amendments) Act 2011 (Cth); Clean Energy (Unit Issue Charge-Auctions) Act 2011 (Cth); Clean Energy (Unit Issue Charge-Fixed Charge) Act 2011 (Cth); Clean Energy (Unit Shortfall Charge-General) Act 2011 (Cth); Clean Energy (Tax Laws Amendments) Act 2011 (Cth).

${ }^{x x i}$ Clean Energy Legislation (Carbon Tax Repeal) Act 2014 (Cth) sch 1 pt 1.

xxii See Section Error! Reference source not found. of this Chapter.

xxiii CFI Act pt 2A; CER, Understanding Contracts (4 April 2016)

http://www.cleanenergyregulator.gov.au/ERF/Want-to-participate-in-the-Emissions-ReductionFund/Step-2-Contracts-and-auctions/understanding-contracts('ERF Contracts').

${ }^{\text {xxiv }}$ Ibid s 20F. 
${ }^{x x v}$ See DoE, Reducing Australia’s Emissions (2014)

$<$ https://www.environment.gov.au/system/files/resources/5acdfbf8-8ced-4c54-a61a-

c06cb31d1e88/files/reducing-australias-emissions.pdf $>$.

xxvi Ibid 1.

${ }^{x x v i i}$ Rudolph et al., above $\mathrm{n}$ vii.

xxviii CPRS White paper, xxxviii

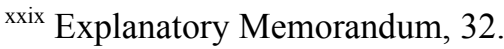

${ }^{\mathrm{xxx}}$ CE Act s 20(4); Clean Energy Regulator, LEPID for the 2013-14 financial year (30 June 2015)

Australian Government $<$ http://www.cleanenergyregulator.gov.au/Infohub/CPM/Liable-Entities-

Public-Information-Database/LEPID-for-the-2013-14-financial-year>.

${ }^{x x x i}$ Rail, domestic aviation and shipping.

xxxii The AUS CPM covered exclusively $\mathrm{CO}_{2}, \mathrm{CH}_{4}, \mathrm{~N}_{2} \mathrm{O}$ and PFCs from aluminium smelting.

xxxiii Rudolph et al., above $\mathrm{n}$ vii.

${ }^{\text {xxxiv }}$ Ibid s 100(7).

xxxv Ibid s 14.

${ }^{\text {xxxvi }}$ CE Act s 14(2).

xxxvii Department of Climate Change, above n 28.

xxxviii CFI Act pt 2A; CER, Understanding Contracts (4 April 2016)

http://www.cleanenergyregulator.gov.au/ERF/Want-to-participate-in-the-Emissions-Reduction-

Fund/Step-2-Contracts-and-auctions/understanding-contracts('ERF Contracts').

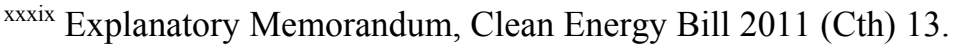

${ }^{\mathrm{xl}}$ Rudolph et al., above $\mathrm{n}$ vii.

xli Explanatory Memorandum, CPRS Bill, 2.39

xlii Ibid ss 121, 123A (8).

xliii Rudolph et al., above $\mathrm{n}$ vii.

${ }^{\text {xliv }}$ CE Act s 100(1).

${ }^{x l v}$ Explanatory Memorandum, Clean Energy Bill 2011 (Cth) 32. 
xlvi Explanatory Memorandum, Clean Energy Legislation Amendment (International Emissions Trading and Other Measures) Bill 2012 and related Bills (Cth) 4.

xlvii Rudolph et al., above $\mathrm{n}$ vii.

xlviii Clean Energy (Unit Shortfall Charge-General) Act 2011 (Cth) s 8(3)(a).

${ }^{\text {xlix }}$ Ibid s 8(3)(b).

${ }^{1}$ CE Act s 135(1)(a)(b).

${ }^{\text {li }}$ Australian Government, 'Australia and European Commission agree on pathway towards fully linking Emissions Trading Systems' (2012) < <ttp://www.climatechange.gov.au/en/media/whats-new/linkingets.aspx $>$.

lii Also see Commonwealth of Australia, 'Strong Growth, Low Pollution: Modelling a Carbon Price. Update' (2011) 96. The estimates were confirmed in the modelling update.

liii Commonwealth of Australia, 'Strong Growth, Low Pollution: Modelling a Carbon Price' (2011).

liv Ibid 98, 113.

${ }^{1 v}$ Tony Wood and Tristan Edis, 'New Protectionism under carbon pricing: case studies of LNG, coal mining and steel sectors' (Grattan Institute, 2011)26.

${ }^{\text {lvi }}$ Ibid.

lvii See Marianna O'Gorman and Frank Jotzo, 'Impact of the Carbon Price on Australia's Electricity Demand, Supply and Emissions' (Centre for Climate Economic \& Policy, 2014).

lviii Ibid. See also Paul Twomey, Obituary: The carbon price UNSW Australia $<$ http://newsroom.unsw.edu.au/news/business/obituary-carbon-price $>$.

${ }^{\text {lix }}$ See Australian Government Department of the Environment and Energy, 'Publications and resources' (2017) Quarterly Updates of Australia's National Greenhouse Gas Inventory $<$ http://www.environment.gov.au/climate-change/greenhouse-gas-measurement/publications $>$.

${ }^{1 x}$ Climate Institute 2017, Research A 2017.

lxi eNGO B 2017; Political Party A, B 2017; Research B, C, D 2017.

Ixii Climate Institute 2017; eNGO A, B 2017.

1xiii Steel Industry 2017, MCA 2017, Natural Resources Industry 2017, Conroy 2017.

Ixiv eNGO A, B 2017; State Government Department 2017. 
1xv Political Party A, B 2017; Conroy 2017.

${ }^{1 x v i}$ See, e.g. Harry Clarke, Iain Fraser and Robert Waschik, 'How much abatement will Australia's Emissions Reduction Fund buy?' (Crawford School of Public Policy, 2014).

${ }^{1 x v i i}$ Schmalensee/Stavins, above n xi, $18 \mathrm{f}$. 